\title{
A Comparison of Facial Proportions in Pleasing and Unpleasing Smile Photographs from Nepalese Population
}

\author{
Basnet $\mathrm{BB}^{1}$ \\ ${ }^{1}$ Assistant Professor, Department of Prosthodontics and Crown-Bridge, College of Dental Surgery. BPKIHS, Dharan, \\ Nepal
}

\begin{abstract}
Introduction: Facial proportion and dental proportions are matters of interest for dental professionals to craft a beautiful smile. In facial analyses, the role of different proportions cannot be overlooked when planning dentofacial treatment. This study aims to determine the different facial proportions; smile index, lower smile index, nose width to outer intercommissural width, intercanine width to outer intercommissural width, nose width to intercanine width and outer intercommissural width to lower facial height in esthetically pleasing smile (ES) and esthetically unpleasing smile (US) groups.

Materials and methods: The frontal smiling photographs $(\mathrm{N}=152,74$ pleasing and 78 unpleasing smile) were gathered and different linear measurements were carried out using digital ruler. The facial proportions were derived and comparisons were made amongst groups and differences were examined in comparison to standard accepted proportion (such as Golden proportion).

Results: Average smile index of ES (5.899 \pm 1.201$)$ was lower than that of US group (6.421 \pm 1.675$)$. The golden proportion was not valid for smile indices in each group. Mean nose width to intercanine width ratio significantly differed in ES and US. The outer intercommissural width to lower facial height was not statistically significantly different from 1:1 ratio.

Conclusion: Most facial proportions in pleasing and unpleasing smiles showed no difference. The outer intercommissural width to lower facial height was found in 1:1 proportion current study with possible utilization in determining vertical dimension of occlusion.
\end{abstract}

Key words: smile, smile index, golden proportion, Nepalese

\section{Introduction}

O mile can transfer a person's range ofemotions $\checkmark$ determining acceptability in a society. ${ }^{1}$ In a person's smile, harmony exist between various components of face such as lips, pupils, teeth and nose. Since evolution, various mathematical proportions were investigated in human face and smile in search for improvement in esthetics.

Conflict of interest: There is no conflict of interest in this study.

Source of funding: This is self-funded study.

\section{*Corresponding Author}

Dr. Bishal Babu Basnet

Assistant Professor

Department of Prosthodontics and Crown-Bridge College of Dental Surgery. BPKIHS, Dharan, Nepal

E-mail: bidrum43@gmail.com
Facial proportions are interest of investigation for dental professionals. ${ }^{2}$ In studying the beauty in face, the argument exist amongst them in regards to symmetry, proportion and ratios. ${ }^{3}$

The Golden proportion or divine proportion is thought to be pivotal in esthetics. ${ }^{4}$ It is a special number (1:1.61803) obtained when we divide a line into two parts and ratio is obtained by dividing longer part by the shorter one which comes equal to the division product of whole length divided by longer part. Paintings such as by Leonardo da Vinci depicted this unique proportion. ${ }^{5}$ There have been many studies testing the validity of golden proportion in the field of dentistry. ${ }^{6-9}$ Much of the studies were focused on the interrelationship of visible portion of anterior teeth. It was examined by 
taking the ratio of apparent mesiodistal widths of anterior teeth from frontal aspect (dividing the apparent mesiodistal width of the central incisor and lateral incisor by that of the lateral incisor, canine respectively). ${ }^{10}$

Proportions and ratios play paramount role to improve the aesthetics of a person. ${ }^{11}$ There are many studies comparing parameters of smile of normal population to the celebrities or influential people. $^{12-15}$ Though relationship between individual teeth are emphasized to possess some proportion in smile, ${ }^{8-10,16,17}$ the preference of overall balance plays an important role in esthetic smile. ${ }^{18}$ In Nepal's context, there are some papers studying dental proportions, ${ }^{17,19,20}$ however, the macroesthetic components were not elucidated in Nepalese smile. In an attempt to abet this research gap, this photographic study aims to compare facial proportions in esthetically pleasing and unpleasing groups and also compare the findings to the standard ratios.

\section{Materials and methods}

Frontal smiling photographs were obtained from volunteers with the inclusion criteria of sound dentition, absence of anterior crossbite, no past history of surgical or orthodontic treatment, no history of trauma in facial regions and no mandibular or craniocervical disorders. Appropriate consent was obtained from the participant before taking the photograph. The protocol was submitted to Institutional Review Committee (IRC) of BPKIHS and ethical approval was sought prior to commencing this study. Participant was seated upright and asked to say "cheese" to get posed smile. Photographs were captured with a digital single reflex camera (D3400, Nikon Corp., Japan) with Nikkor lens $18-55 \mathrm{~mm}$ supported by a tripod.

A total of 152 photos were collected and transferred to computer. Using an electronic ruler (free ruler version 1.7b5, 2003 from http://www.pascal.com/software/freeruler/), the measurements were made in the computer screen.

The photographs were categorized into two groups; with esthetically pleasing smile (ES) and with esthetically unpleasing smile (US); based on various characters of esthetically pleasing smile outlined by Meshramkar et al. ${ }^{11}$ such as display up to second premolar, revealing no gingival recession, closely filled interdental spaces without hyperplasia of gums, display of minimal gingiva, visual symmetry and parallelism of incisal line to lower lip.

Because all the variables analysed in this study are proportions, discrepancy between actual dimensions and photographic dimensions was nullified. The variables measured on photographs are depicted in figure 1. Interalar width was measured from outermost point of right wing to outermost point of left wing of nose; outer intercommissural width was measured from right outer commissure to the left outer commissure; the interlabial gap at smile was measured from the lowest point of maxillary lip to the uppermost point of lower lip at posed smile. Intercanine width was measured between most lateral points of right and left maxillary canines and lower facial height was measured from lowermost point of nose to lowermost point of chin.

From the linear measurements, six proportions were calculated.

Smile index was derived as the ratio between outer intercommissural width and interlabial gap at smile, (B/D in figure 1); lower smile index represents ratio of interlabial gap when smiling to lower third height $(\mathrm{D} / \mathrm{E}$ in figure 1). Also, figure 1 shows nose width to outer intercommissural width (NWOCW, A/B), nose width to intercanine width (NWICW, A/C), outer intercommissural width to lower third height $(\mathrm{OCWLH}, \mathrm{B} / \mathrm{E})$ and intercanine width to outer intercommissural width (ICWOCW, $\mathrm{C} / \mathrm{B})$. Data were entered and analyzed using the 
statistical package for social services (SPSS) for windows software.

\section{Statistical analysis}

Intra-observer reliability was tested by taking 15 randomly chosen measurements taken twice separated by a two-week interval. The correlation between both readings was strong $\left(\mathrm{ICC}=0.990, \mathrm{CI}_{95 \%}=0.971-0.997\right)$ with highly significant level $(\mathrm{p}<0.001)$ indicating excellent reliability. Also, Student's t-test for paired samples showed the absence of significance indicating concordance between mean values at a 5\% significance level.

For all the proportions, normality was ascertained with Shapiro-Wilk test and homogeneity of variances by Levene's test. The smile index, ICWOCW, NWICW and OCWLH were normally distributed in both groups. Lower smile index and NWOCW were not normally distributed in one of the two groups.

The study involved the use of independent $t$ test and Mann Whitney $U$ tests to analyze the proportions in different groups. One-sample t-test was applied to compare the proportions to golden proportion and 1:1 proportion. For all statistical analyses, the level of significance was set to 0.05 (95\% confidence interval).

\section{Results}

Total sample consisted of 152 photographs ( 74 pleasing and 78 unpleasing smile) among them 80 were females (39 pleasing and 41 unpleasing). Smile index was seen to be higher (Table 1) in unpleasing group than that of pleasing group, and, difference was statistically significant $(p=0.028)$. Mean ICWOCW, NWICW and OCWLH of both groups are presented in Table 1. It showed no statistically significant difference in these proportions between two groups $(\mathrm{p}>0.05)$.

Smile index was compared to golden proportion value taking 1.618 as test value. The null hypothesis stating smile index is equal to the golden proportion was rejected in all the groups $(p<0.001)$. Mann-Whitney $U$ test showed that lower smile index statistically differed in two groups $(p=0.047)$ but NWOCW was not statistically different in these two groups $(\mathrm{p}=0.252)$.

In each group, gender-wise comparison was made. The result of independent sample $t$ test is presented in Table 2. Most of the proportions were similar in both genders, nose width to intercanine width ratio was significantly higher in males and outer intercommissural distance to lower third height ratio was significantly higher in females in pleasing smile group $(p<0.05)$. Both of these ratios (NWICW and NWOCW) were significantly higher in males than in females in unpleasing group $(\mathrm{p}<0.05)$.

The nose width to intercanine distance and outer intercommissural distance to lower third height were tested with ratio of 1:1 (Table 3). Onesample $t$ test showed no statistical significant difference observed for OCWLH. This meant the null hypothesis stating OCWLH is close to the ratio $1: 1$ is retained. However, nose width to intercanine width ratio was statistically significantly different from the 1:1 proportion in pleasing and unpleasing smile group $(\mathrm{p}<0.05)$.

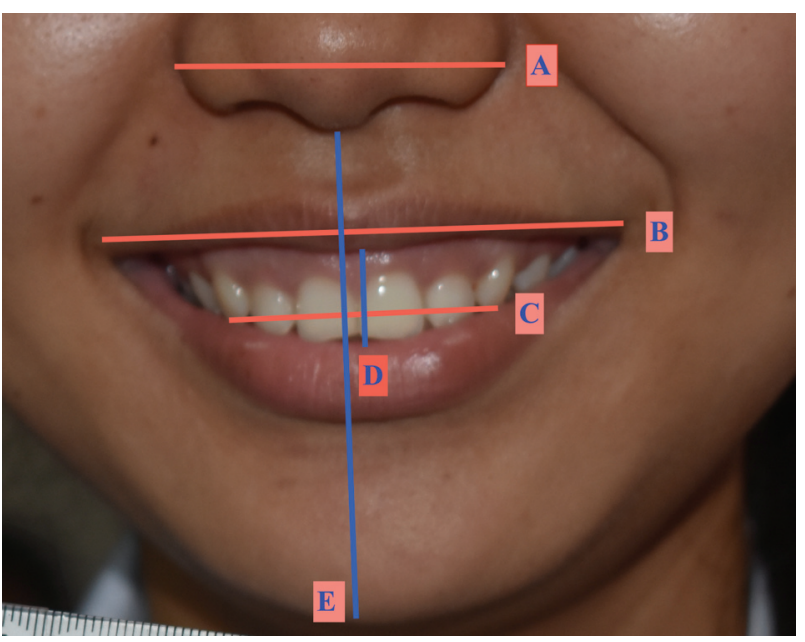

Figure 1: Linear measurements performed in the photographs; $A$ - nose width, B - outer intercommissural width, $C$-intercanine width, $D$ interlabial gap, E-lower third height 
Table 1: Comparison of facial proportions between pleasing and unpleasing smile groups (Independent sample $\mathrm{t}$ test)

\begin{tabular}{|c|c|c|c|}
\hline Proportions & $\begin{array}{c}\text { Pleasing group }(\mathbf{n}=\mathbf{7 4}) \\
\text { mean } \pm \text { SD }\end{array}$ & $\begin{array}{c}\text { Unpleasing group } \\
(\mathbf{n}=\mathbf{7 8}) \\
\text { mean } \pm \text { SD }\end{array}$ & p-value \\
\hline Smile index & $5.899 \pm 1.201$ & $6.421 \pm 1.675$ & 0.028 \\
\hline ICWOCW & $0.645 \pm 0.499$ & $0.648 \pm 0.052$ & 0.731 \\
\hline NWICW & $1.0040 \pm 0.088$ & $1.046 \pm 0.101$ & 0.721 \\
\hline OCWLH & $0.980 \pm 0.094$ & $0.985 \pm 0.117$ & 0.772 \\
\hline
\end{tabular}

Table 2: Gender-wise comparison in each group

\begin{tabular}{|c|c|c|c|c|c|}
\hline Group & Proportion & $\begin{array}{c}\text { Female } \\
\text { mean } \pm \text { SD }\end{array}$ & $\begin{array}{c}\text { Male } \\
\text { mean } \pm \text { SD }\end{array}$ & p-value & Inference \\
\hline Pleasing (ES) & Smile index & $6.086 \pm 1.163$ & $5.690 \pm 1.224$ & 0.158 & NS \\
\hline & $\begin{array}{c}\text { Lower smile } \\
\text { index }\end{array}$ & $0.173 \pm 0.036$ & $0.173 \pm 0.396$ & 0.974 & NS \\
\hline & ICWOCW & $0.653 \pm 0.057$ & $0.635 \pm 0.040$ & 0.124 & NS \\
\hline & NWICW & $1.014 \pm 0.920$ & $1.069 \pm 0.075$ & 0.007 & S \\
\hline & OCWLH & $1.016 \pm 0.092$ & $0.939 \pm 0.079$ & $<0.001$ & S \\
\hline Unpleasing (US) & Smile index & $6.480 \pm 1.698$ & $6.354 \pm 1.670$ & 0.743 & NS \\
\hline & ICWOCW & $0.651 \pm 0.059$ & $0.644 \pm 0.043$ & 0.593 & NS \\
\hline & NWICW & $1.012 \pm 0.105$ & $1.083 \pm 0.083$ & 0.001 & $\mathrm{~S}$ \\
\hline & NWOCW & $0.654 \pm 0.051$ & $0.696 \pm 0.045$ & $<0.001$ & $\mathrm{~S}$ \\
\hline & OCWLH & $0.984 \pm 0.119$ & $0.986 \pm 0.117$ & 0.919 & NS \\
\hline
\end{tabular}

$\mathrm{S}=$ Significant, NS $=$ Not Significant

Table 3: Comparison of facial proportion to 1:1 ratio in pleasing and unpleasing smile groups

\begin{tabular}{|c|c|c|c|}
\hline Smile group & Proportions & p-value & Remarks \\
\hline Pleasing (ES) & OCWLH & 0.069 & NS \\
\hline & NWICW & $<0.001$ & S \\
\hline Unpleasing (US) & OCWLH & 0.256 & NS \\
\hline & NWICW & $<0.001$ & S \\
\hline
\end{tabular}

$\mathrm{S}=$ Significant, $\mathrm{NS}=$ Not Significant

\section{Discussion}

In the present study, mean smile indices of studied pleasing and unpleasing photographs were determined. Contrary to expectations, unpleasing group had higher average smile index $(6.421 \pm 1.675)$ than that of pleasing group $(5.899 \pm 1.201)$. The difference was statistically significant $(\mathrm{p}=0.028)$. Ackerman et al. ${ }^{21,22}$ were the first to introduce smile index and claimed smaller smile index gave younger looks and an esthetic smile possessed a value larger than 5.0. The result of present study showed both groups had esthetic smile based on the smile index but it was lower than that of other populations. ${ }^{13,14,23,24}$ In contrast to current study, Japanese models had higher average smile index $(7 \pm 1.26)$ than young female patients $(5.37 \pm 1.18)$, suggesting well posed esthetic smile in model group. ${ }^{13}$ The average smile index of males in current study (5.690 \pm 1.224 ,ES and 6.354 \pm 1.670, US) were smaller from that of world's influential leaders $(8.040 \pm 4.098)$ but in case of females $(6.086 \pm 1.163, \mathrm{ES}$ and $6.480 \pm 1.698, \mathrm{US})$, consistency was observed to the world's influential female leaders $(6.234 \pm 1.662) .{ }^{14}$ Siddiqui et al. ${ }^{25}$ reported the mean interlabial gap 
and outer intercommissural width for different skeletal patterns. If we derive the smile index, the highest average smile index in their study was for horizontal growers (male, 6.21 and female, 5.98), it was found to be inconsistent to current study (Table 2). In dissensus to current study, attractive group had higher smile index $(6.31 \pm 1.19)$ than unattractive group $(4.64 \pm 1.17)$ in a Chinese study. ${ }^{26}$ One of the explanations of the discrepancy could be attributed to ethnic variations of the studied populations.

Present study suggested significant differences for the smile index from the golden proportion. Several facial proportions were found to be consistent to golden proportion in an Indian study. ${ }^{6}$ In contrast, Golden proportion was not found in female celebrities in another study which accords to current study. ${ }^{27}$

Nose width and intercanine width are thought to be in a ratio of $1: 1 .^{28}$ This was not valid for the pleasing and unpleasing groups in present study. There are other reports which show statistically significant correlation between these two measurements. ${ }^{29-31}$ Interalar width has been thus used extensively to select maxillary teeth in artificial prostheses. ${ }^{29,31-33}$ By and large, this hypothesis was rejected in current study for normal population $(\mathrm{p}<0.001)$. The discrepancy may be attributed to the measurement methods. In those studies the intercanine distance or width was actual sums of mesiodistal widths of maxillary anterior teeth measured intraorally or in the dental casts whereas in current study, the apparent visible distance from the most lateral point of maxillary right canine to the most lateral point of maxillary left canine was measured in photographs as was done in a Japanese study. ${ }^{13}$

Lower smile index is another parameter which relates lower facial height and interlabial gap height at smile. ${ }^{14}$ Lower facial height was assessed with other facial distances ${ }^{34}$ and dental proportions. ${ }^{20}$ Interesting finding of current study was the ratio of outer intercommissural width to lower facial height was in 1:1 proportion for both groups (ES and US). This may add some evidence in the existing interstices in determining occlusal vertical dimension in edentulous patients.

The study showed therewere minimal differences between facial proportions of pleasing smile groups from that of unpleasing smile group. It is better to reevaluate our common notions surmised due to cultural, regional or time-bound background of society. This holds true for the attractiveness perceived by common public ${ }^{35}$ and dental professionals should therefore stick to functional considerations rather than cultural acceptance. $^{12}$

NWICW and NWOCW of unpleasing groups, and NWICW and OCWLH of pleasing group showed sexual dimorphism which corroborates with previous studies ${ }^{36}$ including in Nepalese population. ${ }^{34}$ For other proportions, no statistically significant differences were observed in two sexes.

In current study, assessment of ratios such as nose width to outer intercommissural width (NWOCW), intercanine width to outer intercommissural width (ICWOCW) and outer inter commissural width to lower facial height (OCWLH) was performed. To the author's knowledge, these proportions were innovative assessment in facial analysis. Among these, OCWLH possessed clinical implication with finding of current study for determination or alterations of lower facial height. This was found to be consistent with an Indian study. ${ }^{37}$ The increase in occlusal vertical dimension was reported to affect the smile dimensions such as smile index and interlabial gap but did not impact on the inter commissural width. ${ }^{23}$

In this study, photographs with posed smile were used which is social form of smile and easily repeated. ${ }^{21}$ But videographic analyses are superior to static photographs as suggested by many authors..$^{38-40}$ This is one of the limitations of current study. Schabel et al. ${ }^{41}$ however, argued 
that videography provided more information about dynamic character of smile, photography was an equally useful alternative when used in social smile. Another limitation was the sample size for both groups was smaller in this study. The other important limitation was only lower portion of face was photographed eliminating the chances to examine interpupillary or intercanthal distances. This was resulted from the impediment in taking consent for full-face photography.

Subject to aforementioned limitations, following conclusions were summed up from this study.

1. Most facial proportions showed no statistical difference in pleasing and unpleasing groups. Smile index of pleasing smiles was lower and significantly different from unpleasing smiles.

2. Golden proportion value was not valid for smile index.

3. The outer intercommissural width is in proportion of 1:1 to lower facial height in all the studied groups.

\section{References}

1. Bhuvaneswaran M. Principles of smile design. J Conserv Dent JCD 2010; 13: 225-232.

2. Saurabh R, Piyush B, Sourabh B, et al. Assessment of facial golden proportions among central Indian population. J Int Soc Prev Community Dent 2016; 6: S182-S186.

3. Milutinovic J, Zelic K, Nedeljkovic N. Evaluation of facial beauty using anthropometric proportions. Sci World J; 2014. Epub ahead of print 20 February 2014. DOI: $10.1155 / 2014 / 428250$.

4. Bashour M. Hisotry and current concepts in the analysis of facial attractiveness. Plast Reconstr Surg 2006; 118: 741-56.

5. Sadacharan CM. Vertical and horizontal facial proportions of Indian American men. Anat Cell Biol 2016; 49: 125-131.

6. Khan NA, Nagar A, Tandon P, et al. Evaluation of facial divine proportion in North Indian Population. Contemp Clin Dent 2016; 7: 366370.
7. Chander NG, Kumar VV, Rangarajan V. Golden proportion assessment between maxillary and mandibular teeth on Indian population. $\mathrm{J}$ Adv Prosthodont 2012; 4: 72-75.

8. Forster A, Velez R, Antal M, et al. Width ratios in the anterior maxillary region in a Hungarian population: addition to the golden proportion debate. J Prosthet Dent 2013; 110: 211-215.

9. Jin M-X, Hong M-H, Lee K-J, et al. Does the maxillary anterior ratio in Korean adults follow the Golden Proportion? J Adv Prosthodont 2016; 8: 125.

10. Snow SR. Esthetic smile analysis of maxillary anterior tooth width: the golden percentage. J Esthet Dent 1999; 11: 177-184.

11. Meshramkar R, Agrawal R, Pillal L, et al. A study to evaluate some of the esthetic factors determining attractive smile. Int $\mathrm{J}$ Prosthodont Restor Dent 2016; 6: 31-36.

12. Ferrario VF, Sforza C, Poggio CE, et al. Facial morphometry of television actresses compared with normal women. J Oral Maxillofac Surg 1995; 53: 1008-1014.

13. Murakami Y, Deguchi T, Kageyama T, et al. Assessment of the esthetic smile in young Japanese women. Orthod Waves 2008; 67: 104-112.

14. Orce-Romero A, Iglesias-Linares A, CantilloGalindo M, et al. Do the smiles of the world's most influential individuals have common parameters? J Oral Rehabil 2013; 40: 159-170.

15. Koidou VP, Rosenstiel SF, Rashid RG. Celebrity smile esthetics assessment: Smile angulation. J Prosthet Dent 2017; 117: 636-641.

16. Preston JD. The golden proportion revisited. J Esthet Dent 1993; 5: 247-251.

17. Rokaya D, Kitisubkanchana J, Wonglamsam A, et al. Nepalese Esthetic Dental (NED) Proportion in Nepalese Population. Kathmandu Univ Med J KUMJ 2015; 13: 244-249.

18. Ward DH. A study of dentists' preferred maxillary anterior tooth width proportions: comparing the recurring esthetic dental proportion to other mathematical and naturally occurring proportions. J Esthet Restor Dent Off Publ Am Acad Esthet Dent Al 2007; 19: 324337; discussion 338-339. 
19. Maharjan A, Joshi S. Clinical evaluation of maxillary anterior teeth in relation to golden proportion, RED proportion and golden percentage. J Nepal Health Res Counc 2018; 16: $11-5$.

20. Gyawali R, Singh VP. Maxillary central incisor dimensions and its association with lower anterior facial height. J Coll Med Sci-Nepal 2016; 12: 118-122.

21. Ackerman MB, Ackerman JL. Smile analysis and design in the digital era. J Clin Orthod 2002; 36: 221-236.

22. Ackerman JL, Ackerman MB, Brensinger CM, et al. A morphometric analysis of the posed smile. Clin Orthod Res 1998; 1: 2-11.

23. Chou J-C, Thompson GA, Aggarwal HA, et al. Effect of occlusal vertical dimension on lip positions at smile. J Prosthet Dent 2014; 112: 533-539.

24. Desai S, Upadhyay M, Nanda R. Dynamic smile analysis: changes with age. Am J Orthod Dentofacial Orthop 2009; 136: 310.e1-310.e10.

25. Siddiqui N, Tandon P, Singh A, et al. Dynamic smile evaluation in different skeletal patterns. Angle Orthod 2016; 86: 1019-1025.

26. Wang $\mathrm{C}, \mathrm{Hu} \mathrm{W}$, Liang $\mathrm{L}$, et al. Esthetics and smilerelated characteristics assessed by laypersons. J Esthet Restor Dent 2018; 30: 136-145.

27. Al-Johany SS, Alqahtani AS, Alqahtani FY, et al. Evaluation of different esthetic smile criteria. Int J Prosthodont 2011; 24: 64-70.

28. Ricketts R. The biologic significance of the divine proportion and Fibonacci series. Am J Orthod 1982; 81: 351-70.

29. Mishra MK, Singh RK, Suwal P, et al. A comparative study to find out the relationship between the inner inter-canthal distance, interpupillary distance, inter-commissural width, inter-alar width, and the width of maxillary anterior teeth in Aryans and Mongoloids. Clin Cosmet Investig Dent 2016; 8: 29-34.

30. Deogade SC, Mantri SS, Sumathi K, et al. The relationship between innercanthal dimension and interalar width to the intercanine width of maxillary anterior teeth in central Indian population. J Indian Prosthodont Soc 2015; 15: 91-97.
31. Attokaran G, Shenoy K. Correlation between interalar distance and mesiodistal width of maxillary anterior teeth in Thrissur, Kerala, Indian population. J Int Soc Prev Community Dent 2018; 8: 118-123.

32. Kurien A, Cherian KP, Mhatre S, et al. A comparative study on the relationship between inter alar width, and inter commissural width on circumferential arc width of maxillary anterior teeth in different age groups. J Indian Prosthodont Soc 2014; 14: 352-357.

33. Gomes VL, Gonçalves LC, Prado C jesus D, et al. Correlation between facial measurements and the mesiodistal width of the maxillary anterior teeth. J Esthet Restor Dent 2006; 18: 196-205.

34. Basnet BB, Singh RK, Parajuli PK, et al. An anthropometric study to evaluate the correlation between the occlusal vertical dimension and length of the thumb. Clin Cosmet Investig Dent 2015; 7: 33-39.

35. Pogrel M. What are normal esthetic values. J Oral Maxillofac Surg 1991; 49: 936-69.

36. Peck S, Peck L, Kataja M. Some vertical lineaments of lip position. Am J Orthod Dentofac Orthop Off Publ Am Assoc Orthod Its Const Soc Am Board Orthod 1992; 101: 519524.

37. Abraham A, George J, Peter E, et al. Establishment of a new relationship between posed smile width and lower facial height: A cross-sectional study. Eur J Dent 2015; 9: 394399.

38. Sarver DM, Ackerman MB. Dynamic smile visualization and quantification: part 1 . Evolution of the concept and dynamic records for smile capture. Am J Orthod Dentofacial Orthop 2003; 124: 4-12.

39. Liang L-Z, Hu W-J, Zhang Y-L, et al. Analysis of dynamic smile and upper lip curvature in young Chinese. Int J Oral Sci 2013; 5: 49-53.

40. Beom S-G, Jung J-H, Kim T-Y, et al. A study on the smile of Korean Youth compared with twenty years ago. J Korean Acad Prosthodont 2012; 50: 162-168.

41. Schabel BJ, Baccetti T, Franchi L, et al. Clinical photography vs digital video clips for the assessment of smile esthetics. Angle Orthod 2010; 80: 678-684. 